\title{
Carnets
}

Revue électronique d'études françaises de l'APEF

Première Série - 1 Numéro Spécial | 2009

Cultures littéraires : nouvelles performances \& développement

\section{Escrita como terapia}

Rosa Maria Oliveira

\section{(2) OpenEdition}

1 Journals

Edição electrónica

URL: http://journals.openedition.org/carnets/4043

DOI: $10.4000 /$ carnets. 4043

ISSN: 1646-7698

Editora

APEF

Edição impressa

Data de publição: 1 Junho 2009

Paginação: 299-305

Refêrencia eletrónica

Rosa Maria Oliveira, «Escrita como terapia », Carnets [Online], Première Série - 1 Numéro Spécial | 2009, posto online no dia 16 junho 2018, consultado o 01 maio 2019. URL : http:// journals.openedition.org/carnets/4043; DOI : 10.4000/carnets.4043

\section{(a) $(1) \Theta$}

Carnets est mis à disposition selon les termes de la licence Creative Commons - Atribution - Pas d'utilisation commerciale 4.0 International. 


\section{ESCRITA COMO TERAPIA}

ROSA MARIA OLIVEIRA

Escola EB 2/3 António Dias Simões, Ovar

rmoliveira@aeovar.net

\section{Resumo}

A autora interroga-se sobre o sentido dos acasos nos encontros interpessoais. Este texto relata algumas experiências pessoais de uma autora que recebeu "a Poesia na [sua] juventude como quem recebe um tesouro". ${ }^{1}$

Mots-clés: Rencontres, Déterminisme

Keywords: Meetings, Determinism

\footnotetext{
${ }^{1}$ Resumo da responsabilidade dos editores.

Rosa Maria Oliveira, "Escrita como terapia", Carnets, Cultures littéraires: nouvelles performances et développement, no spécial, automne / hiver 2009, pp. 299-305. 
Não basta nascer. É preciso ainda existir depois, pouco a pouco, como pessoa.

Por várias razões este Encontro (Culturas Literárias - Novas Performances e Desenvolvimento) há-de ser recordado. Como não acredito no acaso, o meu reencontro com a Dra. Hermínia Laurel em Abril deste ano (passados quase 20 anos, ainda era eu aluna universitária) surgiu cheio de sentido.

Mais do que um estímulo, que me leva a esgueirar para dentro de uma ideia que vinha sendo alimentada de leituras e observações, vai ajudar-me a elaborar a síntese de todas as minhas experiências desde que recebi a Poesia na minha juventude como quem recebe um tesouro.

Hoje concentro-me nesta dádiva podendo referir-me a ela como a força que sempre promoveu e conservou a minha saúde a todos os níveis e, à medida que ela foi tecendo a tapeçaria de um universo pessoal, conseguiu também reagir na direcção dos outros. Tornando-se assistência a outrem, é ainda insistência (apoio) para mim mesma face ao risco de dissolução a que todos nós estamos sujeitos. A este nível a escrita transforma-se quase numa lição de sobrevivência.

Assim é também para os dois casos que resgatei à invisibilidade para trazer para este Encontro, esperando que, por entre algumas imprecisões inerentes à própria novidade que é para mim a orientação através da escrita com fins terapêuticos, possa contribuir com ideias, representações e algum material emanados da abertura e do entusiasmo pela descoberta que nada deixa de fora.

A minha prática em Oficinas de Escrita Criativa foi-me mostrando como esta actividade se impregna de vestígios que vão para além da auto-regulação intelectual. $\mathrm{Na}$ realidade, a experiência oficinal enquanto treino para promover a criatividade e o desenvolvimento do próprio pensamento ou para assegurar a consistência inexistente na oralidade vai de certo modo se cristalizando ou dando a sensação de ter deixado de ser aquela motivação procurada pelas escolas como acontecia há uns tempos atrás.

Ficam registados, no entanto, aqueles vestígios de alegria e de bem-estar no seio dos grupos de trabalho no momento da partilha dos seus escritos; ou a surpresa face à descoberta de uma ou outra ressurgência do inconsciente mal explorado. Suponho que, mesmo sabendo o que queríamos das Oficinas de Escrita, é natural que se fizesse mais do que isso. O que principalmente me interessa desta experiência foi o que lá pus sem saber.

De repente, há um verso, uma frase ou um texto que a pessoa escreve e, com ou sem convite, entramos no coração de um trajecto, lá para o meio da vida psíquica alheia, na esperança de poder ajudá-la a recordar-se do ser que ela é, porque como alguns terapeutas 
afirmam nós carecemos do auxílio da Presença que nos informa sobre nossa própria construção como pessoas.

Como Bernard Golse, médico - psiquiatra francês, eu também creio que o que faz a riqueza dos encontros com os outros, com o seu pensamento e os seus escritos é o facto de nada acontecer por acaso.

Mesmo sabendo que assim é, o choque é inevitável quando tomamos consciência daquilo que está a ser decidido para que tudo vá em frente, desde que a nossa vontade de chegar ao interior de todas as partes abra a porta à compreensão. Como as sementes, só há uma forma de nos fazer crescer como pessoas - através do alimento - e aquele alimento que convém para nos tornar capazes dessa assistência aos outros provém do facto de lhes prestarmos verdadeiramente atenção.

A procura de novas leituras tornou-se uma experiência gratificante e, pouco a pouco, dei comigo a entrar no fluxo do conhecimento sobre a natureza humana. Lendo e seleccionando sistemas e teorias que tratam do corpo, da mente e do espírito, com o cuidado de ponderar sobre os exageros ou correntes fixas. Tendo por base um conhecimento geral de psicologia e alguns aspectos de neurolinguística foi bastante enriquecedor acrescentar conhecimentos de Ayurveda (sistema médico antigo da Índia) e de Logoterapia.

Como foi igualmente um privilégio frequentar um centro de Yoga e Terapias, em Aveiro, e, no trabalho e no convívio, ter podido alargar os meus conhecimentos sobre as necessidades terapêuticas do ser humano.

A espiritualidade é a marca subtil destes sistemas, embora em Ayurveda o nível físico seja igualmente importante. Trata-se de um sistema que permite ao bom observador conhecer de forma quase directa o tipo de pessoa que somos. Do exterior, pelos traços físicos, comportamentos e hábitos descobrem-se em parte a nossa realidade interna. Cada ser humano, através dos doshas - mecanismos mecânicos quânticos que governam o fluxo da inteligência e da energia - e em interacção com os desafios, às experiências, os cinco elementos (éter, ar, fogo, água e terra) responde de modo diferente conforme a sua constituição e a qualidade de vida que opta para si. O método dos tridoshas - Pitta, Vata e Kapha - pode ser em parte usado para decifrar alguns dos desequilíbrios, que a escrita eventualmente poderá reparar, vestindo a pele da testemunha silenciosa que incita o ego a desfazer-se das suas racionalizações (no caso de um Pitta) da sua embaraçosa timidez ou falta de memória (de um Vata) ou da lentidão de pensamento (de um Kapha) e ir para além de uma identidade autocriada na base dos velhos hábitos e crenças.

Sabermos que não basta nascer, para usar as palavras de Bernard Golse, que é preciso ainda existir depois pouco a pouco, como pessoa, reforça o sentimento que motiva e nos conduz ao sentido. Esta é também a mensagem da Logoterapia, partindo do princípio 
que a restauração da parte divina na nossa jornada existencial comporta o tratamento para múltiplos aspectos do sofrimento.

É então chegado o momento de apresentar os dois casos que vieram, como um verdadeiro encontro numinoso, tornar possível o estudo comparativo, tendo como base as minhas próprias leituras, a auto e hetero - observação, para além da paixão natural pela descoberta.

Com a permissão das pessoas, passo de seguida a identificá-las:

Caroline Mello, 32 anos, nasceu em Porto Alegre - Brasil, em 1976. Encontra-se em Portugal desde 2006 por um período não superior a dois anos. Curso em Administração de Empresas. É professora de Yoga, Mestre de Reiki e Artista Plástica. No início deste ano, solicitou a minha ajuda para escrever um livro sobre Mandalas.

Júlio Borges Pereira, 55 anos, nasceu em Benguela, Angola, em 1953. Encontra-se em Portugal desde 1975. Curso em Engenharia Metalúrgica. Em 2002 foi convidado para professor da Universidade de Luanda. Desde há um ano está a escrever um Romance Autobiográfico sob a minha orientação.

Nas respostas ao questionário que lhes pedi, com o propósito de orientar esta comunicação, foi referido por ambos que o próprio questionário serviu de terapia pelo facto de os ter feito regressar à génese da própria construção como seres inteligíveis. Pretendia, por um lado, conhecer o percurso de cada um no domínio e na apropriação da língua e culturas escritas, as situações de diálogo, de cooperação e reflexão, a capacidade de agir sobre os próprios textos assim como a questão do perfeccionismo ou da tolerância em relação ao erro. Por outro, visava clarificar o motivo que os levou a escrever uma obra, o percurso de todo o processo de escrita, tendo em conta sentimentos, emoções, os momentos altos e baixos de inspiração e de fluxo, a acção assistida, assim como o sentido da obra realizada.

Caroline Mello frequentou um ensino de qualidade, no Brasil, mas a disciplina de Português não a atraiu. Inclinada para as Ciências, confessa estar arrependida por não ter dedicado mais atenção à Língua Portuguesa. Não se lembra de ter sido encorajada a mudar de atitude ou de ter feito reflexões através da escrita. O despertar para esta vertente só viria acontecer quando passou a trabalhar com Arte-Expressão, já em adulta. Por esta altura, a escrita com fins terapêuticos começou a fazer parte da sua vida juntamente com a Arte. Seguindo as recomendações de uma professora viria a desenvolver uma série artística chamada "Cadernos da Vida" onde fazia reflexões sobre suas pesquisas. Considera-se tolerante em relação ao erro, o que está de acordo com o princípio da Arte - Expressão - o que importa é colocar para fora e não o resultado.

O motivo que a levou a escrever um livro deve-se ao desejo de unir a sua arte com as suas pesquisas sobre o tema "Universo Mandala - a consciência da energia circular ", no 
sentido de despertar nas pessoas a importância de viverem a sua verdade interior. Criar a estrutura e os temas foi fácil, visto tratar-se da síntese do seu trabalho. A verdadeira dificuldade remetia para o desinvestimento na escrita durante os anos de escolarização, agora surgindo sob a forma de vozes desencorajadoras, do género: "ainda não era tempo para um livro" ou "estava a meter-se onde não era chamada".

Quando Caroline me procurou, percebi que a ajuda devia partir de um reforço que estivesse em harmonia com a sua constituição quântica. Sugeri que escrevesse sem se preocupar, as questões linguísticas ficariam comigo. O tipo Dosha Kapha, constituição predominante em Caroline, leva a considerar que existem dificuldades de aprendizagem pela forma lenta ou desatenta como são assimilados os conhecimentos. Contudo, depois do desbloqueio, com estímulo e treino, tornam-se exímios produtores.

Neste momento, Caroline vive a experiência de missão cumprida. O livro publicado pela Editora Ariana será lançado no Porto, no próximo Sábado, dia 4 de Outubro. 0 regresso ao Brasil também está para breve, mas vai fortalecida com a certeza de que valeu a pena ter arriscado um novo posicionamento existencial longe do seu país.

Júlio Borges Pereira usufruiu de um ensino exigente, em Angola. Foi sensibilizado para a leitura de livros relacionada com "os espraiares tropicais" e com a temática dos Descobrimentos. Não houve, no entanto, lugar para a reflexão nem para confronto de ideias. A apropriação da cultura escrita faz-se por um lado, com "Os Lusíadas e, por outro, através das revistas de especialidade onde publica artigos técnicos sobre "engenharia de materiais". Tem tendência para o perfeccionismo.

O motivo que o levou a escrever um Romance Autobiográfico deve-se à falta de qualquer outra solução que curasse feridas profundas. Do sofrimento tirar entusiasmo e atrever-se por campos desconhecidos são aspectos que realmente o movem e manifestamse como a fé.

Uma procura e uma história real que se prolonga por quase trinta anos. A guerra Civil em Angola, no ano de 1975 põe fim a uma história de amor que insiste em existir pela memória. O regresso à matriz a Angola, em 2002, transforma-se numa jornada de rememoração dolorosa. Como fazer luto de um amor com a dúvida que parece trazer a amada de volta à vida? Imagem fantasmada colada à noção de trauma ou realidade?

Quando Júlio me procurou há um ano, vindo pela "mão" de um livro meu, fez-me ver como pus assunto na minha poesia sem saber, qualquer coisa que o levou a dizer: "estou diante de si como um paciente diante de um médico". Naquele momento, pareceu a ambos que a ajuda seria apenas de carácter literário, para dar sentido poético à sua história. Só mais tarde reconheceríamos a dimensão terapêutica deste trabalho de escrita orientada.

No início, a escrita de romance não flúi. Júlio, que tem na mente toda a história, tal como a viveu, concentra-se demasiado na imagem da obra já realizada na divulgação, no 
público - alvo. Num tipo de Dosha Pitta, como Júlio, esconde-se algures uma energia que é um excesso ou um excedente que carece de abrandamento pela compreensão e pelo diálogo firme e autêntico que colmate as descontinuidades da realidade externa, de modo a estabelecer uma continuidade interna que garanta o sentimento de existir na vida e também através de uma obra literária.

Em meados deste ano, Júlio vai encontrando um pouco a estabilidade e a segurança para enfrentar a longa jornada de rememoração. A escrita ajuda a ter fé num sistema de múltiplos significados, à medida que o seu autor avança em cada linha, em cada página. Agora sem pressas, o livro vai fluindo para assegurar e clarificar os laços que dão sentido à matriz da vida depois da corrente do caos e da destruição causada pela guerra.

Júlio apreende a realidade literária como uma versão melhorada do que foi vivido. Enfrenta os cortes de pormenores, obrigando o pensamento a equilibrar o tempo e o número de divagações. O significado da emoção neste trabalho é essencial. Trazer a dimensão de vínculo ou de sintonia com o leitor é não perder de vista que, se quisermos sentir a obra plenamente, temos de fechar o círculo.

Se há um tema que não pode ter conclusão definitiva é mesmo o que é objecto deste trabalho. A escrita posta ao serviço da saúde da pessoa pode funcionar como consciência que falta para nos liberar da pressão de forças que nos movem muitas vezes em direcção Á entropia, isto é, em direcção à desordem ou à incapacidade de atingir certos objectivos. $\mathrm{O}$ caminho é a transformação.

Ainda que desesperados pelas experiências do absurdo, da injustiça ou da simples inibição, pelo poder da escrita podemos pressentir um sentido mais elevado, experimentar no sofrimento uma protecção imensa. Ao reorganizar informações, memórias, emoções, a escrita está a cooperar com a mente que precisa de ordem para se conservar a si mesma. Tal como a meditação, pode ser vista como uma disciplina interna que torna possível a concentração, o alívio das tensões internas, a reflexão sobre os conflitos na consciência, em suma, o auto - conhecimento. Deste modo, aproximamo-nos da elaboração de um mapa cognitivo do nosso próprio mundo que facilita a navegação por entre as diferentes camadas de véus da ilusão. De facto, aquilo a que chamamos realidade só pode ser revelado através de uma construção activa, participando no processo de aquisição e de manutenção de um Eu que se sente muitas vezes levado a remover as montanhas do seu passado e do esquecimento da sua realidade única. Mas se pensarmos como é necessário a totalidade da criação para provocar o momento presente, vamos vivenciá-lo como uma abertura ou uma presença até onde pudermos ir. Se não formos sensatos, afastamo-nos dessa qualidade da vida, de tal modo que tudo parece perto para impedir a felicidade. 


\section{Bibliografia}

ALEIXO, Conceição Antunes, A Vez e a Voz da Escrita, Lisboa, Direcção-Geral de Inovação e de Desenvolvimento Curricular, 2005.

ANDRADE, José Hermógenes, Logoterapia para nervosos, RJ, Edição Record, 1990, 7eedição.

CHOPRA, Deepak, Energia sem Limites, Lisboa, Temas e Debates, 2000.

ChOPRA, Deepak, O livro dos Segredos, Cruz Quebrada, Oficina do Livro, 2004, 3edição.

CSIKSZENTMIHALYI, Mihaly, Novas Atitudes Mentais, Lisboa, Círculo dos Leitores, 1998.

Goleman, Daniel, Inteligência Emocional, Lisboa, Temas e Debates, 1998.

Golse, Bernard, Insistir, Existir, Do Ser à Pessoa, Lisboa, Climepsi Editores, 2001.

LELouP, Jean-Ives, Carência e Plenitude, Petrópolis, RJ, Editora Vozes, 2001.

MAUMOURY, Jean Louis, O riso do sonâmbulo, Lisboa, Teorema, 2002.

Prose, Francine, Ler como um_escritor, Cruz Quebrada, casa das Letras, 2007.

THUnSton, Mark, Designos da Alma - descoberta e cumprimento da Alma, Lisboa, Publicações Europa América. 